\title{
EDUCATING FUTURE MANAGERS IN SOCIAL COMPETENCIES, IN SPAIN: HOW FAR HAVE WE GOT, 20 YEARS AFTER THE BOLOGNA DECLARATION?
}

\author{
Gonzalo Moreno Warleta ${ }^{1}$, Mercedes Rozano Suplet ${ }^{2}$, Alesia Slocum ${ }^{3}, \&$ Anne Schmitz ${ }^{2}$ \\ ${ }^{1}$ Department of Business and Economics, Saint Louis University (Spain) \\ ${ }^{2}$ Department of Finance and Marketing Research, Autonomous University of Madrid (Spain) \\ ${ }^{3}$ Department of Business Administration, CUNEF (attached to the Complutense University (Spain)
}

\begin{abstract}
The original objective of this study was to discover potential improvement areas for teaching social competencies to university undergraduate students. These competencies, often called "soft skills", have become the most demanded capabilities from graduates by employers worldwide. The wider scope of the project became evident when the initial research problem turned out to be the very definition of "competency" itself.

Different sources offered different approaches to its conceptual definition, its classification into different types and to its operationalization. The authors therefore started with the European Tuning Project, a cornerstone of the Bologna agreement, as their base. Up to 5 different classifications were found in the literature, all of them less than 10 years old, and all of them were analyzed, compared, compiled, fused and finally refined into a set of 9 core Interpersonal (Social) Competencies that were established as a "competency framework".

A second research problem was how to evaluate performance: What can be considered an "acceptable" level of achievement? Among the existing options, the Comparator Organizations system was chosen, where the benchmark would be the globally recognized United States Educational system.

Parting from these premises, the authors conducted an empirical study of a valid sample of 225 students in Spain (original sample size above 400) who were studying in either the Spanish or the United States educational systems. Statistically significant differences were found among their behaviors and self-perceptions around certain interpersonal competencies. The survey sought to measure both the students' self-perception (13 questions) and their "real behavior", measured as a declared intention in different hypothetical, "easily-relatable-as-realistic' situations (21 more questions). The reason for choosing this combined methodology, which to the Authors' knowledge had never been used before, lies in the very concept of competency itself, understood to be: a "dynamic combination of knowledge, understanding, skills and abilities". This means that, beyond theoretical knowledge and understanding, competencies are dynamic: they must be put into practice, thereby moving beyond the purely cognitive (at the level of descriptive, self-perception statements, intending to measure qualities respondents believe themselves to have) and into the behavioral arena (at the level of behaviors and/or intents, thereby seeking to measure indicators showing that respondents actually put these behaviors into practice).

The differences found between American-system and European-system students led to a series of interesting conclusions about the status quo of teaching and training social competencies to Business students in Europe, and more specifically in Spain.
\end{abstract}

Keywords: Management learning, competences, interpersonal, leadership, teamwork.

\section{Background}

June 18th, 2019 is the 20th anniversary of the Bologna Declaration, by which 29 European Ministers of Education proposed a European Higher Education Area (currently composed of 49 Countries) in which students and graduates could move freely between countries, thanks to "a system of easily readable and comparable degrees" that should lead to "a system essentially based on two successive cycles, undergraduate and graduate". Systematization and comparability should, thus, be the two main aims of the resulting Bologna Process. 
20 years and 10 governmental meetings later, , Spain, like other European countries, has adopted the European Credit Transfer and Accumulation System (ECTS), striving to evolve from strict convergence in time spent on qualifications, to a competency-based system.

Within the competencies ("dynamic combination of knowledge, understanding, skills and abilities") included in the system there are 3 main types widely recognized in the Literature, starting with the Tuning Project (González \& Wagenaar; 2003), a cornerstone of the Bologna system implementation across European Education Institutions: Instrumental, Interpersonal and Systemic competences

Not to be overlooked, one of the main premises of the European Higher Education Area is that a college degree must guarantee a student's competency in academic, professional and social contexts (Riesco, 2008), leading to an increased employability of graduates. In this same direction, the Observatorio Empleo UAM, 2016 points out Spanish students' perceptions of the most demanded competencies in their current jobs, and their own perceived level of achievement after college. Interpersonal competencies are, by far, the most demanded of the three, while there is still much room for improvement in the teaching of them (scored 3.6/5). The UNESCO report (2006) recognizes that as of 2015 these competencies will be the most demanded by employers, worldwide.

In order to measure the progress made in Spain in terms of education of future managers, as in any performance assessment, one can rely on one of the three following criteria (Johnson, Whittington et al., 2017):

- Compare achievement against the specified goals (Organizational Targets)

- Compare achievement levels over time (Trends over time)

- Compare achievement against a benchmark, typically a competitor (Comparator Organizations)

As Education is a global industry with a wide array of rankings and comparator lists from many different organizations, the third criterion appears to be the most suitable to our case. Gathered evidence shows that, while technical skills (Instrumental competencies) of Spanish graduates in areas such as Chemistry, Physics or Architecture find wide international recognition, quite the opposite seems to happen with degrees in Social Sciences (where Interpersonal competencies happen to gain significant weight). At the same time, Social Sciences degrees account for the largest proportion of Spanish graduates $(23 \%$ of them, according to www.crue.org; 2015) that could be a significant contributing factor to the fact that the Spanish universities usually obtain poor positions in World Education rankings.

Lastly, the prestigious Shanghai Ranking (2016) illustrates that this is not solely a Spanish problem, but rather a European one (as compared with the American Higher Education system).

It is finally worth mentioning that many specific documents ("Reference Points") have been published within the Tuning Project covering the abovementioned Technical and Scientific areas, while little information can be found and consensus is harder to reach among experts in the Social Sciences areas. Instrumental competencies are widely recognized and agreed upon, in the former; Interpersonal competencies, which are admittedly the most important in the Social Sciences find less consensus already from their initial definition and classification, in the latter.

\section{Research objectives}

As a general objective, our original 3-year long project sought to "leverage the learning process of undergraduate students, through the identification, measurement and training in personal and interpersonal competencies, to improve their ultimate professional performance'.

Stemming from this, our goals for the first year, which are the ones presented and discussed in this paper, were listed as:

1. Identify the key competencies for students' professional development.

2. Identify the key performance indicators ("items") of these competencies.

3. Design a framework for measuring the level of achievement in each item.

4. Measure the level of achievement for each student in each competency.

It is worth mentioning at this point that while the first three objectives were expected to consist of a mere literature review, each of these four goals ended up being a challenge in itself, due to the abovementioned lack of consensus among different authors and works analyzed.

The design of the measuring framework and indicators, which seemed simple at first, resulted in a complex task which was solved using qualitative exploratory research, interviewing expert teachers, professors and trainers (Delphi).

\section{Methodology}

In order to Identify the key competencies for students' professional development, it was necessary to first define the term competency within the educational system, the backbone of the European Tuning Project. González \& Wagenaar (2003) defined competency as a dynamic combination of knowledge, 
understanding, capabilities and abilities that the student acquires throughout the learning process. This is not to be confused with learning outcomes, which are the results of the learning process, or formulations of what the students must know, understand or be able to demonstrate at the end of the learning process. It becomes apparent that competencies should be measured through observable behaviors that indicate the level attained at any one time time, and preferably not through self-assessment, as has been done in most research to date.

Secondly, competencies must be classified and grouped into sound categories. A consensus can be found in the literature around Generic Competencies, those that are not specific to any one area, and that can be classified into Instrumental, Interpersonal and Systemic competencies. Most consensus reaches this point, but goes no further: hardly a $75 \%$ coincidence can be found between classification lists, like the LatAm Tuning project, or the Sonora University Competency list for the Chemistry degree, among others. The authors need to create a list of Interpersonal Competencies, based on the abovementioned diverse sources. The final list of 9 Interpersonal competencies includes:

1. Critical thinking and Self-Criticism

2. Teamwork

3. Interpersonal Abilities

4. Ability to work in Multidisciplinary Teams

5. Ability to communicate with experts from diverse areas

6. Appreciation of Diversity and Multiculturalism

7. Ability to work in International contexts and Global awareness

8. Ability to acquire Ethical Commitments

9. Leadership

In the second place, aiming to "identify the key performance indicators ("items") to these competencies", the Authors elaborated a list of observable behaviors related to the definition of each of the listed 9 competencies. As an example, two different approaches to "Teamwork" were described using up to 11 observable variables ("Items").

Designing a framework for measuring the level of achievement in each item was the third step. At this point, while reviewing the existing literature at hand, the Authors decided to create a questionnaire divided into 2 main blocks, separating Self-perception, frequently used as the only measuring tool; and Behavior, an innovation based on the previous work (developing observable behaviors as "Items" of each competency), and which is expected to represent a significant contribution of this work.

Lastly, Measuring the level of achievement for each student in each competency was done through a 40-questions survey. A Likert scale was used in most cases, with an open percentage to indicate the level of agreement with a set of 34 statements (21 Behavioral intents and 13 descriptions of Self-Perceptions).

The fieldwork took place between May 2018, mainly but not exclusively among students from the Autonomous University of Madrid and Saint Louis University, and resulted in 427 interviews, out of which 275 were finally fully validated. Qualtrics was the selected tool for the Survey. The results were developed using SPSS for analysis and Excel for tables and presentations.

\section{Results}

The first task was to conduct an exploratory Factor Analysis for 2 sets of data, where these were:

- Behavioral Variables, where 13 of the original 21 items merged into 3 constructs/factors, accounting for $52.2 \%$ of the variance. We named these factors:

○ Behaviors tending to facilitate Teamwork and Appreciation of Diversity

- Personally Mature behaviors, exhibiting such values as Empathy or Assertiveness

○ Behavioral Leadership

- Self-perception Variables, where 12 of the 13 original items merged into 3 surprisingly coincidental constructs/factors, accounting for $60.8 \%$ of the Variance. Factors where, thus the same ones:

○ Self-perceptions related to values like Teamwork and Appreciation of Diversity

- Perceived Leadership

- Self-perception of Maturity values, such as Empathy or Assertiveness

The names attributed to each factor/construct was based on the items it comprised, and as a result of this procedure, only 9 of the original 34 items were discarded.

We then proceeded to analyze the Variance (ANOVA) among different sets of data, using the specifically collected segmentation variables (Age, Gender, Educational System, etc.). As was stated from the beginning, in the project objectives, the main goal was to uncover and analyze the differences existing between European and American Educational Systems students in terms of Interpersonal competencies. Since employability rankings attributed better results to the latter, the idea was to find out if students from both systems effectively differed in their behaviors and self-perceptions, regarding these competencies. 
The main results of ANOVA uncovered statistically significant differences between the several groups and for different Factors, among which we focused on differences between European-system and American-system students, regarding three factors:

- Behaviors that facilitate Teamwork and demonstrate Diversity tolerance and appreciation

- Behaviors that demonstrate Leadership competencies

- Self-Perceived Leadership

These two groups turned out to be the most different of all, in statistical terms: out of all the personal characteristics of a student (segmentation variables) such as gender, age, institution they attended, etc., the single one that best predicts a difference in the students' Interpersonal Competencies is the Educational System (European or American) they attended to.

Self-perceived Leadership seems to be the most complex of all the constructs, showing the larger number of differences between Groups, while Behavioral Leadership only shows differences per the Age and the Educational System. The construct Appreciation of Diversity and Teamwork shows differences between the Educational System groups and also between the Institution-based (Public or Private) segmented groups. Lastly, the Behavioral construct Personal Maturity only shows differences per age groups which, as stated above, should be naturally expected.

To end this discussion, we shall agree that while the Analysis of Variance (ANOVA) indicates the abovementioned differences between segments, it does not at all prioritize the variables that suffer the highest variations, nor does it show "the sense" of these differences (what could be interpreted as "who is more X than whom"). In order to obtain this kind of information the sample was segmented in Excel, using the variables indicated by ANOVA, and both subsamples where analyzed separately, on a question-by-question basis. Without disregarding the results of ANOVA, we can pepper their interpretation using this user-friendly system, leading us to conclude that European-system and American-system students differ in their development of Interpersonal Competencies.

\section{Conclusions}

Focusing on the differences between European and American educational systems and stemming from the analysis it becomes apparent that the most differential items are concentrated in Behaviors tending to facilitate Teamwork and Appreciation of Diversity. At the same time, based on the sign of the statements, and the sense of the difference (positive or negative), we can state that, in general terms, European-system students appear to be more tolerant of Diversity and stronger Team players. It is very important, at this point, to keep in mind that we are not talking about the student's nationality (cultural background should be discarded as a potential bias). In both educational system samples European and American students were equally present and mixed.

Continuing with the analysis, items which clustered around the construct Behavioral Leadership show smaller differences, yet statistically significant, according to ANOVA. According to the sense of these statements and the given answers, the Item Communication seems to be equally strong in both segments, while Planning, and even more Influence indicate that American-system students hold a stronger position.

Lastly, Items concentrating around Self-perceived Leadership, which exhibits highly significant differences between segments, according to ANOVA: It is not to be overlooked that this factor showed the highest number of significant differences between segments (age, gender, institution, etc.). Admittedly, Leadership is not an easy concept, and the following statement, attributed to Warren Bennis, states it clearly: "To a certain extent, Leadership is like beauty: it is hard to define, but you recognize it the moment you see $i t$ ". While it is frequently presented as an important personal characteristic, a skill, and ability... this importance may also open a door to biased self-perceptions. We can conclude that, when it comes to Self-perceived Leadership, European-system students are less Resilient, and even less capable of Solving Interpersonal Conflicts, but above all they perceive themselves as less inclined or prepared for Leadership. Back to Bennis, since the 1960's he advocated for a democratic and humanistic leadership as the best way to deal with a complex, ever-changing environment, and this appreciations are extremely suitable for our final conclusion: While European-system students are less qualified to behave as Leaders, and they are certain in their self-perception in this regard, our system seems to better prepare them for the future challenges at the workplace, by making them significantly more tolerant to Diversity and individual differences, and stronger Team players. This opens a door to hope for our younger generations, in terms of their potential professional success in the Global Workplace. 


\section{References}

Bhuiya, C. (2018). The skills gap is real: 8 skills you didn't know you needed.

González, J. Y Wagenaar, R. (2003). «The Tuning Educational Structures in Europa Project (2002).» Bilbao: Universidad De Deusto.

La Vanguardia (2018). Las 10 habilidades más valoradas en el mercado laboral.

Mckinsey Global Institute (2018). Skill shift automation and the future of the workforce. Dsicussion paper. Disponible en www.mckinsey.com/mgi

Observatorio Empleo Uam (2016). Informe inserción laboral.

QS Rankings (2018). World University Rankings.

Riesco, M. (2008). El enfoque por competencias en el EEES y sus implicaciones en la enseñanza y el aprendizaje. (U. A. Educación, Ed.) Tendencias pedagógicas, vol. 13, pp 79-105.

Rozano, M., Escat, M. Y Rubio, L. (2017). Coaching para la mejora de competencias profesionales: una aplicación a la asignatura "prácticas en empresa". XXVII Jornadas Hispano-Lusas de Gestión Científica-Localización y dinámicas competitivas en un entorno global. Alicante, 1-16.

Shanghai Ranking`S (2016). Academic Ranking of World Universities in Social Science.

Solans, A. Y Nuñez, R.M. (2008). Elaboración de un cuestionario para la evaluación de competencias genéricas en estudiantes universitarios. Apuntes de psicología, vol. 26, núm. 1, pp. 35-49.

Times Higher Education Ranking.

Top Universities Employability Ranking.

UNESCO (2006). Teachers and Educational quality: monitoring global needs for 2015. Montreal: Unesco Institute for Statistics.

Whetten, D.A., \& Cameron, K.S. (2005). Desarrollo de competencias directivas. Ed. Pearson (6 $6^{\mathrm{a}}$ Ed.).

* For a complete list of sources and references, please refer to the authors. 